\title{
Formulation and Evaluation of Gliclazide in Vegetable Oil-Based Self Emulsifying Delivery System
}

\author{
Gehan F. Balata \\ Department of Pharmaceutics, Faculty of Pharmacy, Zagazig University, Zagazig, Egypt.
}

\section{ARTICLE INFO \\ Article history: \\ Received on: 05/05/2018 \\ Accepted on: 17/07/2018 \\ Available online: 30/09/2018}

\section{Key words:}

gliclazide, solid-SEDDS, ternary phase diagram,

dissolution, olive oil.

\begin{abstract}
Objectives: To formulate a poorly water-soluble, antidiabetic drug, gliclazide, in the vegetable oil-based selfemulsifying delivery system (SEDDS), as a trial to improve its dissolution and hence its bioavailability. Material and methods: Solubility of gliclazide was investigated in different vegetable oils, surfactants and co-surfactants. The system was selected and the self-emulsification region was identified. Drug-loaded SEDDS was prepared and evaluated in terms of emulsification time, phase separation, droplet size and rate of drug dissolution. The formulation that showed good self-emulsifying properties, acceptable droplet size and high $\%$ drug release was further processed into solid- SEDDS by physical mixing with varying proportions of a mixture (2:1) of microcrystalline cellulose and lactose and characterized for crystalline, droplet size and in vitro drug dissolution properties. Results and Conclusions: Formulation of gliclazide in liquid and solid SEDDS using olive oil resulted in significant $(\mathrm{P}<0.05)$ improvement in its dissolution properties. Both differential scanning calorimetry and $\mathrm{x}$-ray diffraction studies demonstrated the presence of gliclazide in the molecular state in all the prepared solid formulations. Solid SEDDS of gliclazide containing a lower proportion of adsorbent (G1) had comparable dissolution properties with its liquid form. Thus formulation of gliclazide in the solid self-emulsifying system may be a promising strategy to improve its dissolution properties.
\end{abstract}

\section{INTRODUCTION}

Type 2 diabetes mellitus is a serious health problem in Egypt associated with high mortality rates due to macrovascular and microvascular complications (Hegazi et al., 2015).

Gliclazide, a second-generation hypoglycemic sulfonylurea, is the drug of choice in prolonged therapy for the control of Type 2 diabetes mellitus (Harrower, 1994). It stimulates insulin secretion from pancreatic beta cells (Jung et al., 1999) and increases the sensitivity of the peripheral tissue to insulin (Shavi et al., 2010). Gliclazide shows low aqueous solubility and consequently slow and variable gastrointestinal absorption with low bioavailability after oral administration (Palmer and Brogden, 1993). The solubility and dissolution rate of gliclazide had been improved by different methods including inclusion complexes with beta-cyclodextrin (Sapkal et al., 2007), solid dispersion with different carriers (Biswal et al., 2008; 2009) and surface solid

${ }^{*}$ Corresponding Author

Gehan F. Balata, Department of Pharmaceutics, Faculty of Pharmacy,

Zagazig University, Zagazig, Egypt.E-mail:gf_balata@yahoo.com dispersion (Mahajan et al., 2012). Continuing that research, the self-emulsifying delivery system was suggested to improve the solubility and dissolution rate of gliclazide.

Currently, lipid-based formulations have gained much interest as carriers for the oral delivery of poorly water-soluble drugs (Pouton, 2006). Self-emulsifying drug delivery system (SEDDS) is an example which is defined as a mixture of oil, surfactant, and co-surfactant that forms oil-in-water emulsion upon gentle agitation condition provided by gastrointestinal motion (Pouton, 2000). SEDDSs are capable of improving the oral bioavailability of many poorly water-soluble drugs (Tuleu et al., 2004). The large interfacial area generated by these small droplets promotes drug diffusion into intestinal fluids. In addition, the digestion of lipid-based formulations by bile salts, phospholipids, and cholesterol, induces a change in lipid composition and results in the formation of different colloidal phases including micelles, vesicles, and liquid crystalline phases in the intestinal lumen (Fatouros et al., 2007) and consequently improves the absorption of administered drugs (Iosio et al., 2008). It was reported that the presence of the drug in an oil droplet protects the drug from 
enzymatic or chemical degradation and activates lipoproteins promoting the lymphatic transport of lipophilic drugs (Craig, 1993). Moreover, emulsion droplets lead to a faster distribution of the drug in the gastrointestinal tract and hence minimizing the irritation due to the contact between the drug and the gut wall (Franceschinis et al., 2011). However, liquid SEDDS has many disadvantages that include: low drug loading capacity, drug leakage, low stability, incompatibility problems with the capsule shell and possibility of irreversible drugs/excipients precipitation (Kallakunta et al., 2012). Alternatively, solid- SEDDS has been already produced by loading liquid SEDDS on solid carriers using different technologies: extrusion/spheronisation (Iosio et al., 2008), wet granulation in high shear mixer (Franceschinis et al., 2005), spray drying (Yi et al., 2008) and physical mixing (Dixit and Nagarsenker, 2008). Solid SEDDS offer many advantages which include: stability, facility of manufacturing, can easily be packed in hard gelatin capsules and disperse freely in the gastrointestinal tract. In general, solid SEDDS combine the advantages of lipidbased drug delivery systems with those of solid dosage forms (Kallakunta et al., 2012).

Oils play a crucial role in the formulation of selfemulsifying formulations. Both long and medium chain triglyceride oils with different degrees of saturation are commonly used in the preparation of SEDDS (Khedekar and Mittal, 2013). Dietary vegetable oils with antioxidant activity such as olive oil and linseed oil are reported to be effective in cardiovascular diseases and associated metabolic disorders, including hyperglycemia and dyslipidemia (Berraaouan et al., 2013; Samarji and Balbaa, 2014; Kaithwas and Majumdar, 2012).

Previous literature reported the formulation of liquid and solid self-emulsifying system of gliclazide using Capryol 90 as the oil phase (Wankhade et al., 2012; Nipun and Ashraful Islam, 2014). The aim of this study is to incorporate gliclazide in vegetable oil-based solid-SEDDS in an attempt to improve its solubility and dissolution rate and hence its bioavailability. Liquid SEDDS was prepared using vegetable oil, Tween 80 as surfactant and propylene glycol as co-surfactant. Then the optimized formula was adsorbed on a mixture of microcrystalline cellulose and lactose by physical mixing and studied for its efficiency in improving drug dissolution properties.

\section{MATERIAL AND METHODS}

Gliclazide was obtained as a gift sample from Delta Pharma, Egypt. Tween 80, Tween 20 and Propylene glycol (PG) were purchased from Merck Specialities Pvt. Ltd., Mumbai. Polyethylene glycol 400 (PEG 400), Methanol, Soybean oil, Olive oil, Palm oil, Sunflower oil and Sesame oil were purchased from SD Fine Chemicals, Mumbai. Avicel PH 101 (Microcrystalline cellulose (MCC)) and Lactose were purchased from FMC
BioPolymer, USA

\section{Saturation solubility study}

Vegetable oils are one class of lipid solvents that are safe as they are fully digested and absorbed after oral administration (Mohanvarma and Padavala, 2013). So, the solubility of gliclazide was determined in various vegetable oils, as well as, surfactants and co-surfactants. An excess amount of gliclazide (50 mg) was added to $5 \mathrm{ml}$ of the selected vehicles in capped vials and the mixtures were sonicated (Ultrasonic model SS101H, Sonix IV, Huntington Beach, CA, USA) at $40-50^{\circ} \mathrm{C}$ to facilitate drug solubilization. Then the mixtures were transferred to a thermostatic shaker water bath (LSB-030S, Daihan Lab Tech Co., LTD, Indonesia) maintained at $25^{\circ} \mathrm{C}$ for $48 \mathrm{hr}$. After reaching equilibrium, vials were centrifuged (Nuve, NF 815, Ankara, Turkey) at $4000 \mathrm{rpm}$ for $10 \mathrm{~min}$ and followed by filtration through a membrane filter (No $0.45 \mu \mathrm{m}$ ). The clear filtrate was diluted with methanol and measured spectrophotometrically at $226 \mathrm{~nm}$ (Apel Co., Ltd., Japan) (Palmer and Brogden, 1993). Triplicate measurements were taken and Mean $\pm \mathrm{SD}$ was recorded.

\section{Construction of ternary phase diagram \& formulation optimization}

Based on the results of solubility studies, oil, surfactant, and cosurfactant showing highest solubility of gliclazide were selected for construction of the phase diagram. Different blends were prepared using varying concentrations of oil $(20,30,40$ and $50 \%, \mathrm{w} / \mathrm{w}$ ). Surfactant and cosurfactant (Smix) at each oil percentage were mixed by vortexing (JL6001-G/L, Mettler Toledo Co., Switzerland) in different weight ratios $(1: 1,2: 1,3: 1$ and $4: 1 \mathrm{w} / \mathrm{w}$ ) (Table 1). About $0.2 \mathrm{ml}$ of each blend was introduced into $100 \mathrm{ml}$ of distilled water and the contents were mixed gently with a magnetic stirrer (magnetic stirrer, Thermolyne, Dubuque, IA, USA) at $100 \mathrm{rpm}$ for $2 \mathrm{~min}$ at room temperature. The diluted products were inspected for clarity, phase separation and coalescence of droplets. Emulsions showing phase separation, cracking and coalescence of oil droplets were judged as unstable emulsions (Aboutaleb et al., 2016). Phase diagram was constructed to identify the self-emulsifying region using CHEMIX software.

\section{Preparation of gliclazide SEDDS}

SEDDS formulations with gliclazide were prepared by adding the weighed amount of drug (Each $1 \mathrm{~g}$ formulation contained $40 \mathrm{mg}$ of gliclazide) to surfactant followed by addition of co-surfactant and oil in a glass vials (Table 2). The resultant mixtures were stirred continuously by vortex mixing and heated at $40^{\circ} \mathrm{C}$ to obtain a homogeneous isotropic mixture. The SEDDS formulations were stored at ambient temperature until further use (Kallakunta et al., 2012).

Table 1: Composition of different oil, surfactant and cosurfactant blends.

\begin{tabular}{|c|c|c|c|c|c|c|c|c|c|c|c|c|c|c|c|c|}
\hline $\begin{array}{l}\text { Ingredients } \\
\text { (mg) }\end{array}$ & A1 & A2 & A3 & A4 & B1 & B2 & B3 & B4 & $\mathrm{C} 1$ & $\mathrm{C} 2$ & $\mathrm{C} 3$ & $\mathrm{C} 4$ & D1 & D2 & D3 & D4 \\
\hline Olive oil & 200 & 200 & 200 & 200 & 300 & 300 & 300 & 300 & 400 & 400 & 400 & 400 & 500 & 500 & 500 & 500 \\
\hline Tween 80 & 400 & 533.3 & 600 & 640 & 350 & 466.7 & 525 & 560 & 300 & 400 & 450 & 480 & 250 & 233.3 & 375 & 400 \\
\hline PG & 400 & 266.7 & 200 & 160 & 350 & 233.3 & 175 & 140 & 300 & 200 & 150 & 120 & 250 & 166.7 & 125 & 100 \\
\hline
\end{tabular}


Table 2: Different formulations of gliclazide SEDDS.

\begin{tabular}{ccccccc}
\hline $\begin{array}{c}\text { Ingredients } \\
(\mathbf{m g})\end{array}$ & $\mathbf{A 3}$ & $\mathbf{A 4}$ & $\mathbf{B 3}$ & $\mathbf{B 4}$ & $\mathbf{C 3}$ & $\mathbf{C 4}$ \\
\hline Gliclazide & 40 & 40 & 40 & 40 & 40 & 40 \\
Olive oil & 200 & 200 & 300 & 300 & 400 & 400 \\
Tween80 & 600 & 640 & 525 & 560 & 450 & 480 \\
PG & 200 & 160 & 175 & 140 & 150 & 120 \\
\hline
\end{tabular}

\section{Characterization of SEDDS}

\section{Assessment of emulsification time}

The emulsification time for different formulations was determined using Dissolution Tester apparatus II, rotating paddle (SP6-400, G.B. CALEVA Ltd., Dorset, England). One gram of each formulation was added to $500 \mathrm{ml}$ of distilled water with gentle agitation at $70 \mathrm{rpm}$ and at a temperature of $37^{\circ} \mathrm{C}$. The time to form homogenous nanoemulsion was determined (Abdalla et al., 2008).

\section{Stability studies}

\section{(a) Phase separation \& drug precipitation study}

Since SEDDS are subjected to dilution in GIT after oral administration, so the ability of the prepared SEDDS to be diluted easily without any drug precipitation was determined. Different gliclazide SEDDS formulations were exposed to 100 and 500 folds dilution with distilled water. Examined formulations were stored at $25^{\circ} \mathrm{C}$ for $24 \mathrm{~h}$ and observed visually for phase separation and drug precipitation (Yin et al., 2009).

\section{(b) Refrigeration thaw cycle}

A single refrigeration thaw cycle was performed by taking $2 \mathrm{ml}$ sample of each formulation which subjected to refrigeration at $2^{\circ} \mathrm{C}$ for $24 \mathrm{~h}$ then thawing at $40^{\circ} \mathrm{C}$. The samples were then observed for phase separation and drug precipitation.

\section{(c) Centrifugation}

A $5 \mathrm{ml}$ sample of each formulation was centrifuged (REMI,11, Cama Industrial Estate, Walbhat Road, Goregaon East, Mumbai - 400063, India) at 4,000 rpm for $5 \mathrm{~min}$. Thereafter, the samples were observed for phase separation and drug precipitation.

\section{Determination of droplet size}

The mean size of emulsion globules was determined by Zetasizer (Malvern Instruments, Malvern, UK) based on dynamic laser scattering. The dispersed formulations were measured after dilution $(1: 1000 \mathrm{v} / \mathrm{v})$ with distilled water and mix for 1 minute with Cyclo mixer

\section{In-vitro drug dissolution from liquid SEDDS}

The in vitro dissolution test was performed in $900 \mathrm{ml}$ distilled water maintained at $37 \pm 0.5^{\circ} \mathrm{C}$ using USP Dissolution Tester apparatus II rotating at $70 \mathrm{rpm}$ (SP6-400, G.B. CALEVA Ltd., Dorset, England). The SEDDS formulations (containing an amount equivalent to $40 \mathrm{mg}$ gliclazide) were filled into hard gelatin capsules (size 00) and used for drug release studies compared with the plain drug. Samples $(5 \mathrm{ml})$ were withdrawn and replaced with fresh media after 5, 10, 15, 20, 30, 40, 50 and $60 \mathrm{~min}$. Samples were filtered using a $0.45 \mu \mathrm{m}$ filter and analyzed spectrophotometrically for gliclazide at $226 \mathrm{~nm}$. Triple measurements were conducted for each formulation, and data presented as means \pm SD. Percentage of cumulative drug dissolution at different time intervals was calculated and a graph plotted versus time. The dissolution data were analyzed in terms of initial dissolution rate over the first 10 min of dissolution (IDR $=\%$ dissolved $/ \mathrm{min}$ ) (Kallakunta et al., $2013)$ and dissolution efficiency after $60 \mathrm{~min}\left(\mathrm{DE}_{60}\right)$ which was calculated from the area under the dissolution curve at time ' $\mathrm{t}$ ' (measured using the trapezoidal rule) and expressed as percentage of the area of the rectangle described by $100 \%$ dissolution in the same time (Khan, 1975).

\section{Formulation of solid SEDDS}

The liquid SEDDS that exhibited acceptable emulsification efficiency and high dissolution parameters was selected for preparation of solid SEDDS, in three different ratios (liquid SEDDS:carrier mixture ratio was 1:1, 1:2 and 1:3 w/w). The formulations G1-G3 were prepared with a carrier mixture of MCC: lactose, $2: 1 \mathrm{w} / \mathrm{w}$. The liquid SEDDS was triturated with a mixture of MCC and lactose using a mortar and a pestle. The wet mass was passed through sieve No.120 and was dried at ambient temperature (Bhagwat and D'Souza, 2012).

\section{Characterization of solid SEDDS}

\section{Differential scanning calorimetry (DSC)}

The DSC thermograms of gliclazide, MCC, lactose and different solid SEDDS formulations were recorded using differential scanning calorimeter (Perkin Elmer, USA). The samples were heated in an open aluminum pan from 35 to $200^{\circ} \mathrm{C}$ at a scanning rate of $10^{\circ} \mathrm{C} / \mathrm{min}$ under the stream of nitrogen.

\section{$X$-ray diffraction studies (XRD)}

$\mathrm{X}$-ray diffraction measurements of gliclazide, MCC, lactose and different solid SEDDS formulations were carried out with X-ray diffractometer (X'Pert PRO PA Nalytical, USA). XRD patterns were recorded at room temperature using monochromatic CuKa-radiation over a range of $2 \theta$ angles from $3^{\circ}$ to $50^{\circ}$ with an angular increment of $0.02^{\circ}$ per second.

\section{Determination of droplet size}

Droplet size of the dispersed solid SEDDS was determined using the same procedure as mentioned before for liquid SEDDS.

\section{In-vitro drug dissolution}

An amount of powder equivalent to $40 \mathrm{mg}$ gliclazide was filled into hard gelatin capsules (size 00) and the dissolution of gliclazide from different solid SEDDS formulations were done under the same conditions as mentioned before for liquid SEDDS.

\section{RESULTS AND DISCUSSION}

\section{Saturation solubility study}

Identifying the suitable oil, surfactant and co-surfactant having the maximal solubilizing potential for gliclazide is the 
key factor for optimum drug loading and stability during storage (Miryala and Kurakula, 2013). The solubility of gliclazide in the screened vegetable oils, surfactants and co-surfactants is presented in Figure 1. Gliclazide exhibited high solubility in olive oil (1.09 $\mathrm{mg} / \mathrm{ml})$, tween $80(2.01 \mathrm{mg} / \mathrm{ml})$ and PG $(1.94 \mathrm{mg} / \mathrm{ml})$. Accordingly, olive oil, Tween 80 (surfactant) and PG (co-surfactant) were further used for the construction of ternary phase diagram.

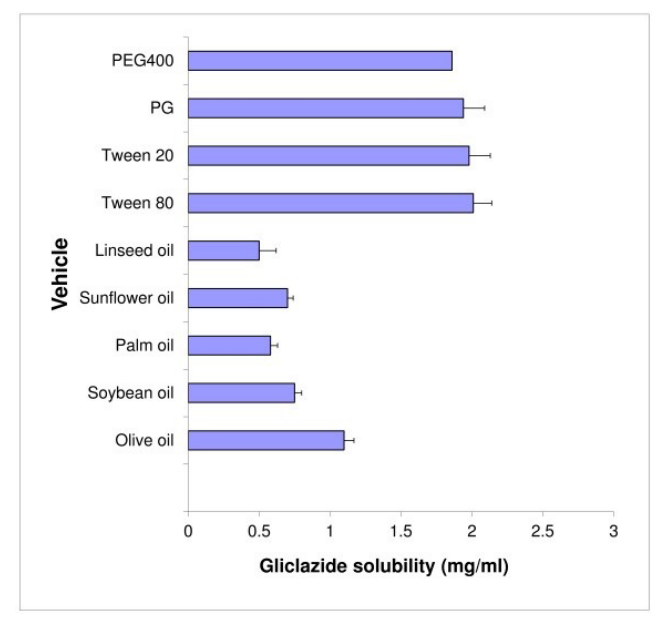

Fig. 1: Solubility of gliclazide in different vegetable oils, surfactants and cosurfactants (Mean $\pm \mathrm{SD})$.

Superior gliclazide solubility in olive oil than the other investigated oils may be ascribed to its higher ester value (190.86). It was reported that the solvent capacity of oils for drugs is mainly dependent on the concentration of ester groups (Zambiazi et al., 2007). It is known that the ester value is a measure of the percentage of glycerol present in oil (Azeem et al., 2009).

Tween 80 , a hydrophilic nonionic surfactant of HLB = 15 and has a high solubilizing capacity (Kallakunta et al., 2012). It was reported that nonionic surfactants with high HLB values (1215) facilitate the immediate formation of oil-in-water emulsions and rapid spreading of the formulation in aqueous media (Azeem et al., 2009). In addition, nonionic surfactants are most commonly used in oral formulations because of their lower irritation potential and toxicity, a wide range of compatibility, good physicochemical stability and being less affected by $\mathrm{pH}$ (Gershanik and Benita, 2000; Basalious et al., 2010). No remarkable difference of gliclazide solubility in either Tween 80 or Tween 20. However, Tween 80 was expected to produce better emulsification than Tween 20. Generally, surfactants are defined as molecules with polar heads and hydrophobic tails. Tween 20 is 20 -mole ethoxylate of sorbitan monolaurate (12 C) while Tween 80 is 20 -mole ethoxylate of sorbitan mono oleate $(18 \mathrm{C})$. Thus, Tween 80 has a longer hydrophobic tail and expected to have bigger packing parameter and hence larger curvature of oil/water interfacial film with better emulsification (Mosca et al., 2013; Zeing et al., 2017).

For efficient emulsification, a single surfactant may not be able to produce the required reduction in $\mathrm{O} / \mathrm{W}$ interfacial tension and fluid interfacial film, so the addition of co-surfactant is crucial. PG acts as a co-surfactant that is required to increase the flexibility of the interfacial film between oil and water and enable the dissolution of a large quantity of the drugs in the oil phase (Nepal et al., 2010). The flexibility of the surfactant film is necessary to facilitate the existence of different structures including droplet-like shapes, aggregates and bicontinuous structures which enhance drug dissolution (Amemiya et al., 1999). In addition, PG increases the penetration of the oil phase into the surfactant hydrophobic tail thereby further decreases the interfacial tension (Zeing et al., 2017). Propylene glycol exhibited slightly higher solubilization capacity of gliclazide than polyethylene glycol that may be ascribed to a difference in surface tension of both alcohols i.e. $45.6 \mathrm{dyne} / \mathrm{cm}$ for $\mathrm{PG}$ compared to $48.4 \mathrm{dyne} / \mathrm{cm}$ for $\mathrm{PEG}$ (ACCU Dyne TestTM, www.accudynetest.com/visc_table.html; Talegaonkar et al., 2008).

\section{Construction of ternary phase diagram \& formulation optimization}

Construction of ternary phase diagrams gives an idea about the nature of the diluted dispersions and consequently, assists in selecting optimum proportions of oil, surfactant, and co-surfactant. The ternary phase diagram of olive oil - Tween 80 - PG in different ratios was constructed (Figure 2) and the results of visual observations of the diluted blends are represented in Table 3. It is clear that blends containing $20-40 \% \mathrm{w} / \mathrm{w}$ of oil produced clear and stable emulsions with increasing Smix ratios (formulations A3, A4, B3, B4, C3, C4) whereas the resultant emulsions of blends with lower Smix ratios (formulations A1, A2, $\mathrm{B} 1, \mathrm{~B} 2, \mathrm{C} 1, \mathrm{C} 2$ ) resulted in translucent emulsions followed by phase separation.

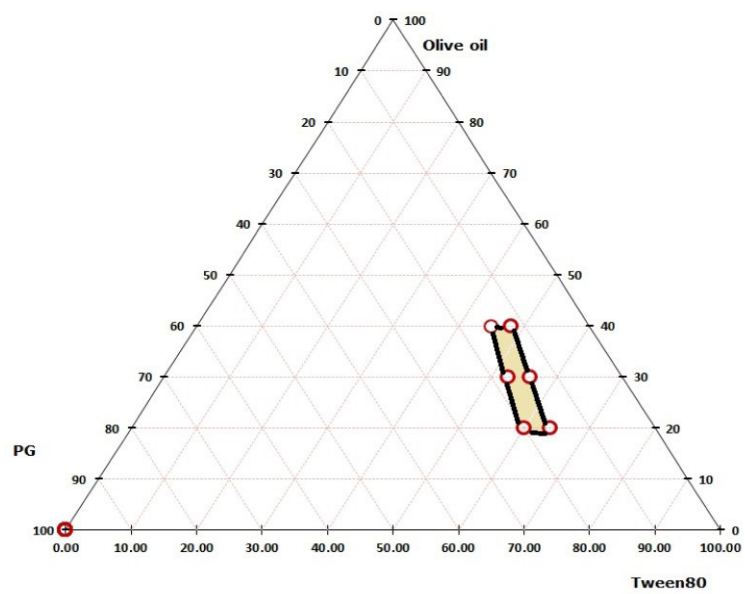

Fig. 2: Ternary phase diagram of SEDDS consisting of olive oil, Tween 80 and PG.

Moreover, formulations containing higher oil content $(50 \% \mathrm{w} / \mathrm{w})$ produced milky emulsions with oil droplets on the surface when diluted with water.

According to the ternary phase diagram, formulations contained olive oil $(20-40 \% \mathrm{w} / \mathrm{w})$, Tween 80 : PG ratio $(3: 1 \&$ $4: 1, \mathrm{w} / \mathrm{w})$ were selected for the formulation of gliclazide loaded SEDDS.

The results revealed that high Smix ratios (3:1 \& 4:1 w/w) with an oil concentration of no more than $40 \% \mathrm{w} / \mathrm{w}$ was important for the emulsification efficiency which was in agreement with the results reported by Czajkowska-Kośnik et al., 2015. This result may be explained on the basis of the presence of sufficient amounts of surfactant and co-surfactant to be adsorbed at oil/water interface thus reducing the free energy for emulsion formation and 
also prevent coalescence of dispersed droplets resulting in stable nanoemulsions (Levy and Benita, 1990). Agubta et al., 2014, reported that efficient oil and water emulsification require the presence of a high concentration of surfactant to provide very low interfacial tension $\left(\leq 10^{3} \mathrm{mN} / \mathrm{m}\right)$. Gurram et al., 2015, reported that large molecular volume oils including long-chain triglycerides such as olive oil require higher surfactant concentration than short chain mono/diglycerides.

Table 3: Formulation optimization.

\begin{tabular}{ccc}
\hline Formulations & Clarity & Stability \\
\hline A1 & translucent & Phase separation \\
A2 & translucent & Phase separation \\
A3 & clear & stable \\
A4 & clear & stable \\
B1 & translucent & Phase separation \\
B2 & translucent & Phase separation \\
B3 & clear & stable \\
B4 & clear & stable \\
C1 & translucent & Phase separation \\
C2 & translucent & Phase separation \\
C3 & clear & stable \\
C4 & clear & stable \\
D1 & milky & Phase separation \\
D2 & milky & Phase separation \\
D3 & milky & Phase separation \\
D4 & milky & Phase separation \\
\hline & & \\
\hline & & \\
\hline
\end{tabular}

Presence of co-surfactant is essential for the emulsification process. The flexibility of the interfacial film which is imparted by the presence of co-surfactant allows the exchange of co-surfactant from the interfacial film to continuous phase and dispersed phase and exchange of surfactant between the interfacial film and water and hence good emulsion formation (Bagwe et al., 2001). However, only small amounts of co-surfactant (Smix of $3: 1 \& 4: 1)$ is required for the stability of the formed emulsion as large amounts lead to an expansion of the interfacial film with a subsequent increase in droplet size (Saifee et al., 2013). In addition, higher amounts of co-surfactant results in precipitation of drug upon dilution due to the partitioning of co-surfactant into the aqueous phase (Lawrence and Rees, 2009).

\section{Characterization of SEDDS}

\section{Assessment of self-emulsification}

The results of self-emulsification are given in Table 4 . Emulsification time varied from $31 \mathrm{~s}$ to $81 \mathrm{~s}$. The emulsification time was directly proportional to the amount of oil phase and inversely proportional to Smix ratio. This result may be due to the presence of higher concentration of tween 80 that has high ability to reduce the interfacial tension between $\mathrm{O} / \mathrm{W}$ interface which in turn shows a positive impact on spontaneous emulsification process (Bhikshapathi et al., 2013). Agubata and coworkers, 2014, reported that ease of emulsification is dependent on the ease with which water penetrates the oil-water interface with the formation of liquid crystalline phase resulting in rapid emulsification.
Furthermore, increasing oil concentration results in increased viscosity of the formulation and hence prolonged emulsification time. Similar results were reported by Harshal et al., 2011.

Table 4: Emulsification time, droplet size and dissolution parameters of gliclazide loaded in olive oil based SEDDS compared with the plain drug (mean $\pm \mathrm{SD}, \mathrm{n}=3$ ).

\begin{tabular}{ccccc}
\hline Formulation & $\begin{array}{c}\text { Emulsification } \\
\text { time (Sec) }\end{array}$ & $\begin{array}{c}\text { Droplet size } \\
\text { (nm) }\end{array}$ & $\begin{array}{c}\text { IDR } \\
(\% \text { per } \text { min })\end{array}$ & DE (\%) \\
\hline Plain drug & NA & NA & $1.5 \pm 0.05$ & $27.9 \pm 0.78$ \\
A3 & $40 \pm 1.7$ & $230 \pm 5.6$ & $5.1 \pm 0.59$ & $59.9 \pm 1.64$ \\
A4 & $31 \pm 1.2$ & $215 \pm 2.3$ & $5.8 \pm 0.57$ & $66.8 \pm 5.1$ \\
B3 & $53 \pm 2.3$ & $263 \pm 3.5$ & $7 \pm 0.57$ & $76.4 \pm 5.5$ \\
B4 & $45 \pm 1.5$ & $245 \pm 2.8$ & $8.0 \pm 0.75$ & $86.3 \pm 3.5$ \\
C3 & $81 \pm 3.1$ & $411 \pm 5.2$ & $5.1 \pm 0.39$ & $68 \pm 2.82$ \\
C4 & $77 \pm 3.5$ & $360 \pm 3.4$ & $5.4 \pm 0.55$ & $66.1 \pm 1.24$ \\
\hline
\end{tabular}

IDR: initial dissolution rate after $10 \mathrm{~min}$.

DE\%: dissolution efficiency \% after $60 \mathrm{~min}$.

\section{Stability studies}

All SEDDS samples which were subjected to appropriate dilutions and storage for $24 \mathrm{~h}$, single refrigeration/thawing cycle or centrifugation were found to be stable with no evidence of phase separation or drug precipitation suggesting that diluted gliclazide SEDDS can remain stable in gastrointestinal fluids.

\section{Determination of droplet size}

Since the rate and extent of drug release, as well as its gastrointestinal absorption, mainly depend upon emulsion droplet size, the droplet size of the prepared formulations was determined and the results are represented in Table 4. The formulations had droplets size in the range of $215-411 \mathrm{~nm}$.

It was clear that droplet size decreased with the increase in Smix which was consistent with previous studies. (Ostertag et al., 2012; Mehrnia et al., 2016) At high Smix, there will be a great reduction in interfacial tension with surfactant diffusion into the aqueous phase facilitating the formation of fine droplets. On the other hand, at low Smix, the surfactant concentration at the oilwater interface will not be enough to completely cover the surface of drops; coalescence of droplets occurs and hence increased droplets size (Zeing et al., 2017).

The droplet size was negatively affected by the oil concentration. This result may be explained on the basis of collision theory. As the concentration of oil increased, a larger number of emulsion droplets will be formed and consequently will collide with each other resulting in the formation of larger droplets (Shahavia et al., 2015).

\section{Contour plot}

The two-dimensional contour plots were drawn to understand the variation of emulsification time and droplet size with oil concentration and Smix (Figure 3A \& B). At low oil concentration and high Smix, rapid emulsification $(<40 \mathrm{sec})$ and small droplet size $(<250 \mathrm{~nm})$ were obtained.

\section{In-vitro drug dissolution from liquid SEDDS}

Figure 4 and Table 4 demonstrate the dissolution profiles 
and dissolution parameters of gliclazide from different SEDDS formulations, respectively. Table 5 summarizes the results of the ANOVA analysis. The dissolution parameters (IDR \& DE\%) of gliclazide from all SEDDS formulations were significantly $(P=$ 0.000 ) higher than the plain drug. The maximal drug dissolution was obtained from the formulation B4 (containing oil of $30 \% \mathrm{w} / \mathrm{w}$ and surfactant/co-surfactant ratio of $4: 1, \mathrm{w} / \mathrm{w})$. The formulation B4 exhibited IDR of $8.0 \pm 0.75$ compared to only $1.5 \pm 0.05$ obtained by the plain drug, comprising a 5.3 -folds increase in the initial dissolution rate within $10 \mathrm{~min}$. Moreover, the dissolution efficiency exhibited by the formulation B4 after 60 min was 86.3 $\pm 3.5 \%$ compared to only $27.9 \pm 0.78 \%$ exhibited by the plain drug comprising a 3.1 -folds increase in drug dissolution efficiency. This result may be ascribed to the presence of the drug in free molecular state or in emulsion form or in solubilized micellar solution when the formulation is subjected to aqueous medium compared to the crystalline form of the plain drug (Kallakunta et al., 2012). Moreover, the optimum dissolution properties (IDR \& $\mathrm{DE} \%$ ) achieved by the formulation B4 may be due to the proper balance between oil percentage and a surfactant system.

Table 5: Analysis of variance for the different SEDDS formulations compared with the plain drug.

\begin{tabular}{|c|c|c|c|c|c|c|c|c|c|c|c|c|}
\hline \multirow[t]{2}{*}{ Value } & \multicolumn{2}{|c|}{$\begin{array}{c}\text { Effect of the } \\
\text { formulation of SEDDS } \\
\text { (Plain drug against } \\
\text { different SEDDS) }\end{array}$} & \multicolumn{2}{|c|}{$\begin{array}{c}\text { Effect of oil \% at Smix } \\
\text { 3:1 (A3, B3, C3) }\end{array}$} & \multicolumn{2}{|c|}{$\begin{array}{c}\text { Effect of oil \% at Smix } \\
4: 1(\mathrm{~A} 4, \mathrm{~B} 4, \mathrm{C} 4)\end{array}$} & \multicolumn{2}{|c|}{$\begin{array}{c}\text { Effect of Smix at } 20 \% \\
\text { oil }(A 3, A 4)\end{array}$} & \multicolumn{2}{|c|}{$\begin{array}{c}\text { Effect of Smix at } 30 \% \\
\text { oil (B3, B4) }\end{array}$} & \multicolumn{2}{|c|}{$\begin{array}{c}\text { Effect of Smix at } 40 \% \\
\text { oil (C3, C4) }\end{array}$} \\
\hline & IDR & DE\% & IDR & DE\% & IDR & DE\% & IDR & DE\% & IDR & DE\% & IDR & DE\% \\
\hline P-value & 0.000 & 0.000 & 0.007 & 0.004 & 0.005 & 0.000 & 0.227 & 0.089 & 0.14 & 0.039 & 0.453 & 0.346 \\
\hline $\mathrm{R}^{2}$ & $94.79 \%$ & $97.6 \%$ & $80.55 \%$ & $83.64 \%$ & $83.2 \%$ & $92.54 \%$ & $33.71 \%$ & $55.55 \%$ & $45.82 \%$ & $69.63 \%$ & $14.72 \%$ & $22.19 \%$ \\
\hline $\mathrm{R}^{2}$ adjusted & $92.56 \%$ & $96.58 \%$ & $74.07 \%$ & $78.19 \%$ & $67.6 \%$ & $90.05 \%$ & $17.13 \%$ & $44.44 \%$ & $32.27 \%$ & $62.04 \%$ & $0.00 \%$ & $2.74 \%$ \\
\hline S-value & 0.54 & 3.26 & 0.536 & 3.66 & 0.627 & 3.36 & 0.59 & 3.78 & 0.67 & 4.26 & 0.46 & 2.14 \\
\hline
\end{tabular}
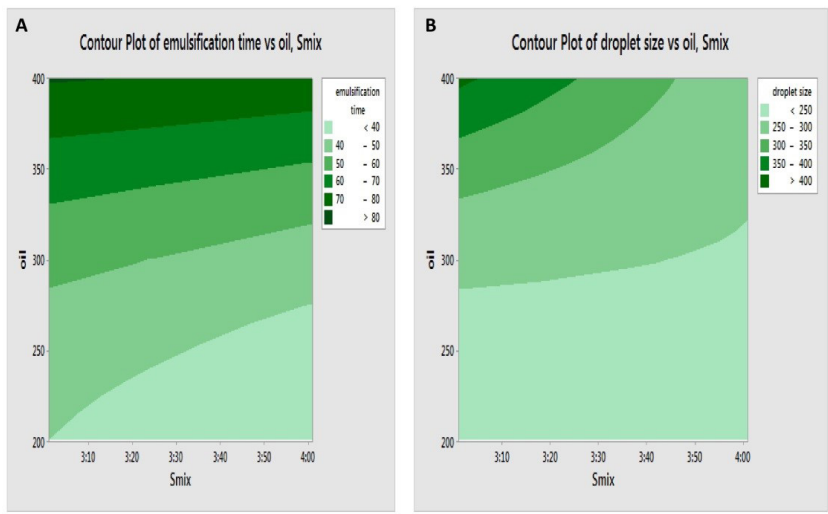

Fig. 3: Contour plots for the effect of oil concentration and Smix on (A) emulsification time; (B) droplet size.

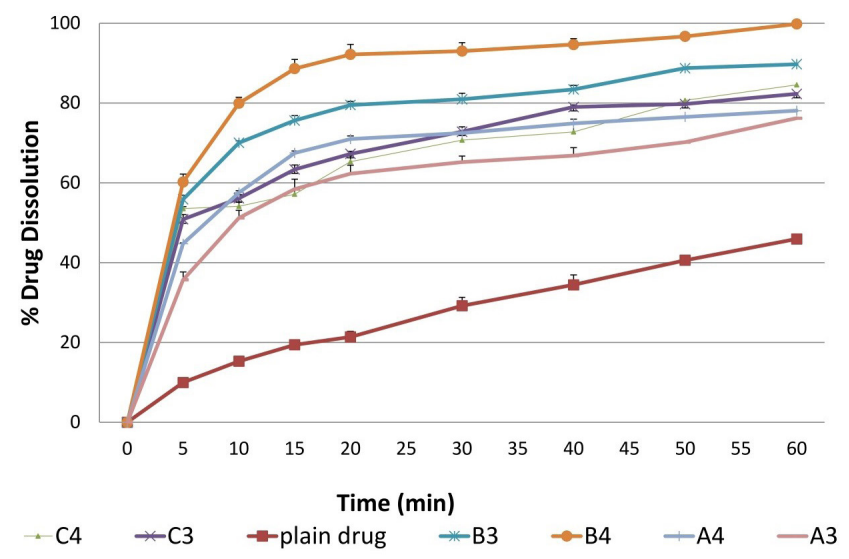

Fig. 4: In vitro dissolution profiles of gliclazide from liquid SEDDS formulations compared with the plain drug (mean $\pm \mathrm{SD}, \mathrm{n}=3$ ).

The results revealed that both IDR and $\mathrm{DE} \%$ were negatively affected by oil concentration, droplet size and emulsification time (nonsignificant effect) and positively affected by Smix (nonsignificant effect), Table $5 \&$ Figure 5 . These results were in agreement with Nigade et al., 2012, who reported that surfactant concentration, oil/surfactant ratio, the polarity of the emulsion, droplet size and charge are critical parameters for oral drug absorption from SEEDS. Presence of excess surfactant in the formulation promotes the effective dispersion of the drug in the dissolution medium by the solubilization process, in addition to promoting drug spreading in fine oil droplets with larger surface area exposed to the dissolution medium (Suresh and Sharma, 2011). Moreover, the reduction in drug dissolution from formulations containing a higher percentage of oil $(>30 \% \mathrm{w} / \mathrm{w})$ may be due to the presence of insufficient proportion of surfactant and hence lesser reduction in interfacial tension between oil and aqueous phase followed by decreased drug partition into an aqueous medium (El-Laithy, 2008).

Values of correlation analysis are presented in Table 6 and Figure 6. Generally, the Pearson Correlation Coefficient (r) shows the nature and strength of correlation. The coefficient can vary between -1 and +1 while zero value describes no correlation. A positive sign of coefficient indicates a synergistic effect while a negative term indicates an antagonistic effect upon the response. It is clear that there was a nonsignificant correlation between dissolution parameters (IDR and DE\%) and oil \% and Smix. Alternatively, there was a strong positive significant correlation $(r>0.9, P<0.05)$ between oil \%, droplet size and emulsification time.

\section{Formulation of solid SEDDS}

Generally, liquid SEDDS suffers from many disadvantages such as leakage from capsules, handling and stability problems and difficulty in capsule filling. For our study, the selected SEDDS that showed good dissolution properties was (B4) which contained $30 \% \mathrm{w} / \mathrm{w}$ olive oil and hence it will be advantageous to convert the formulation into the solid form to increase the oxidative stability of olive oil and protect the formulation against rancidity. 


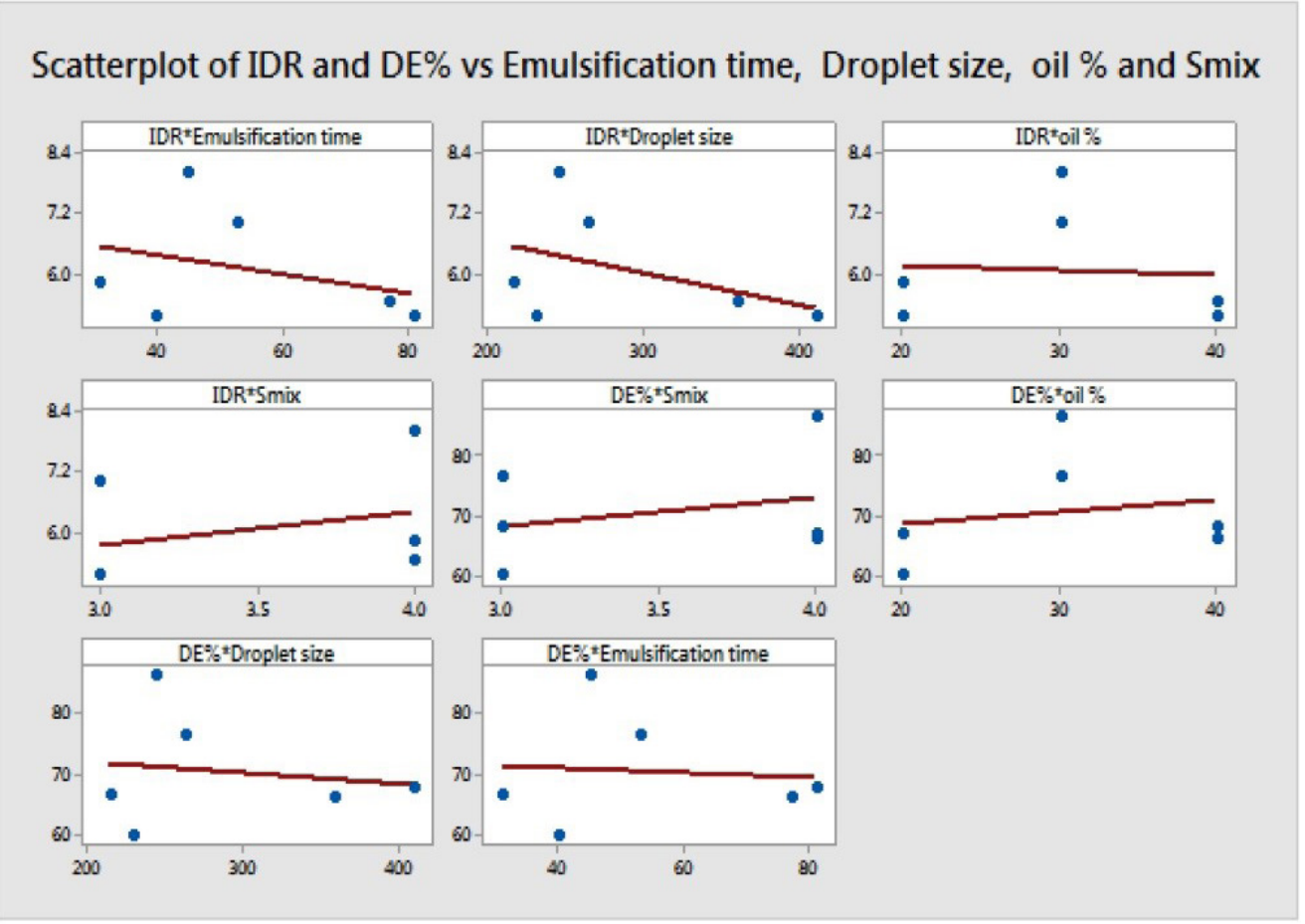

Fig. 5: Correlation between IDR and DE\% versus oil percentage, emulsification time, droplet size and Smix.

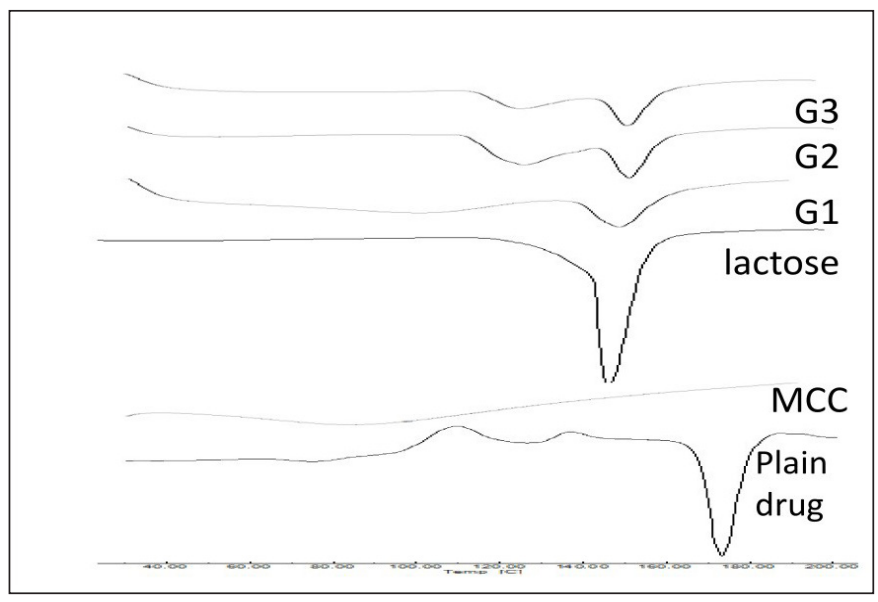

Fig. 6: Differential scanning calorimetric thermograms of plain gliclazide, MCC, lactose and different solid SEDDS.

The results showed that it was possible to convert the selected liquid SEDDS (B4) into solid forms with all liquid SEDDS:carrier mixture ratios used, while attempts to produce solid forms with higher proportions of liquid SEDDS (SEDDS:carrier mixture $=2: 1$ ) failed.

The selection of MCC was done on the basis of possessing high intraparticle porosity with good water swelling properties, as well as high adsorption capacity for lipid-based preparations (Parekh et al., 2017). Since MCC is a water-swellable polymer so it forms a network like structure in water which prevents nucleation, crystal growth and precipitation of drug upon dilution of SEDDS in GIT (Dokania and Joshi, 2015). In addition, MCC is a hydrogen bonding polymer which can form an intermolecular hydrogen bond with gliclazide resulting in retardation of drug precipitation upon dilution in GIT (Chen et al., 2012).

Lactose is a water-soluble solid carrier with a small molecular weight which may provide good preservation of nanoemulsion droplet size after dilution (Li et al., 2013).

Table 6: Results of correlation analysis of IDR and DE\% versus oil percentage, emulsification time, droplet size and Smix.

\begin{tabular}{cccccc}
\hline Factor & & $\begin{array}{c}\text { Emulsification } \\
\text { time (min) }\end{array}$ & $\begin{array}{c}\text { Droplet size } \\
(\mathbf{n m})\end{array}$ & $\begin{array}{c}\text { IDR } \\
(\% \text { per min) }\end{array}$ & Oil \% \\
\hline \multirow{2}{*}{ Droplet size (nm) } & $\mathrm{r}$ & 0.978 & & & \\
& $\mathrm{P}$ & 0.001 & & & \\
IDR (\% per min) & $\mathrm{r}$ & -0.334 & -0.422 & & \\
& $\mathrm{P}$ & 0.518 & 0.405 & & \\
Oil \% & $\mathrm{r}$ & 0.958 & 0.919 & -0.076 & \\
& $\mathrm{P}$ & 0.003 & 0.01 & 0.887 & \\
Smix & $\mathrm{r}$ & -0.189 & -0.193 & 0.309 & 0.00 \\
& $\mathrm{P}$ & 0.72 & 0.714 & 0.552 & 1.00 \\
DE\% & $\mathrm{r}$ & -0.088 & -0.153 & 0.953 & 0.177 \\
& $\mathrm{p}$ & 0.886 & 0.773 & 0.003 & 0.773 \\
\hline
\end{tabular}

IDR: initial dissolution rate after $10 \mathrm{~min}$.

DE\%: dissolution efficiency \% after $60 \mathrm{~min}$.

\section{Characterization of solid SEDDS}

\section{Differential scanning calorimetry (DSC)}

The DSC thermograms of plain gliclazide, MCC, lactose and different solid SEDDS are illustrated in Figure 6. The thermogram of the plain drug showed a sharp melting endotherm at $173.3^{\circ} \mathrm{C}$ with $\Delta \mathrm{H}=-150 \mathrm{~mJ}$ indicated the presence of the drug in the crystalline state (Shavi et al., 2010). MCC showed 
a broad peak at $85.24^{\circ} \mathrm{C}$ with $\Delta \mathrm{H}=-22.96 \mathrm{~mJ}$. Lactose showed a sharp endothermic peak at $153.4^{\circ} \mathrm{C}$ with $\Delta \mathrm{H}=-327.11 \mathrm{~mJ}$. No representative peaks for gliclazide were detected in all the prepared solid SEDDS with predominance of excipients peaks indicating the transformation of crystalline structure of gliclazide into molecularly dissolved state (Kallakunta et al., 2012).

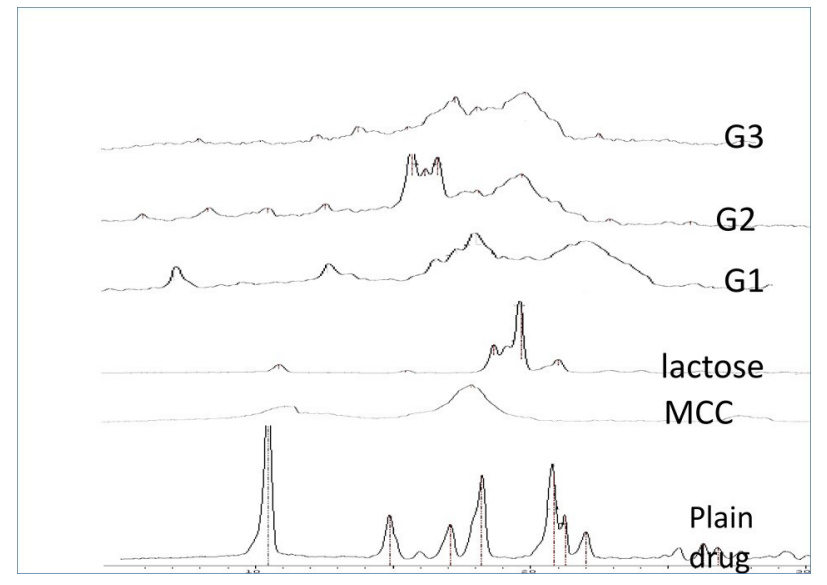

Fig. 7: X-ray powder diffraction spectra of plain gliclazide, MCC, lactose and different solid SEDDS.

\section{$X$-ray diffraction studies (XRD)}

The XRD patterns of plain gliclazide, MCC, lactose and different solid SEDDS are shown in Figure 7. The diffraction pattern of gliclazide showed high-intensity peaks at $2 \theta$ of 10.59 , $14.98,17.2,17.85,18.15,22.07$ and $25.42^{\circ}$ confirmed the crystalline nature of pure gliclazide (Biswal et al., 2009). Pure MCC showed three peaks at $2 \theta$ of 15,16 and $23^{\circ}$. Lactose had distinct peaks at $2 \theta$ of $12.6,19,20$ and $21^{\circ}$. The XRD patterns of all the prepared solid SEDDS showed the absence of drug peaks with a predominance of excipients peaks which may be due to the transformation of gliclazide into molecularly dissolved form in all the prepared solid SEDDS (Bhandari and Avachat, 2015).

\section{Determination of droplet size}

Droplet size of the different solid SEDDS (G1-G3) after dispersion compared with the corresponding liquid formulation (B4) was presented in Table 7 and Figure 8. The droplet size of the resultant nanoemulsions from different solid preparations was in the range of $265-560 \mathrm{~nm}$. The PDI values of the solid SEDDS (G1) and liquid SEDDS (B4) were below 0.3 indicating good uniformity in the globule size distribution after dilution with water (Jaiswal et al., 2014).

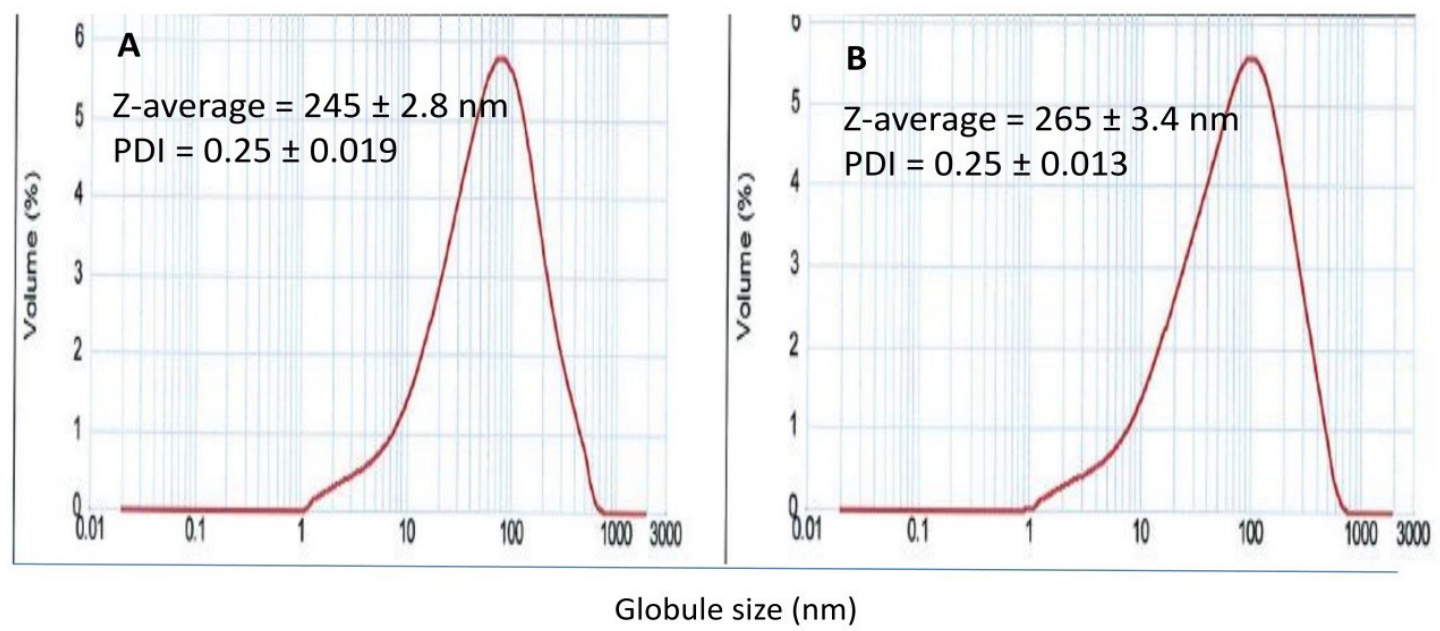

Fig. 8: Globule size distribution of (A) liquid SEDDS, B4, compared with (B) solid SEDDS, G1.

Comparing the droplet size of liquid SEDDS with those of the dispersed solid SEDDS, one can detect that they are significantly higher although still in the nano-size range which is required for absorption. In addition, the amount of adsorbent mixture had a positive significant effect on the droplet size. Jaiswal and coworkers reported that the presence of MCC as an adsorbent in the solid SEDDS leads to increase in globule size during dispersion of the formulations (Jaiswal et al., 2014). MCC hydrates and swells in water forming fibrils on which hydrophilic surfactant molecules adhere to its surface. So, MCC interferes with the complete reconstitution of the emulsion from the solid SEDDS results in a reduction in surfactant concentration at $\mathrm{O} / \mathrm{W}$ interfaces with a subsequent increase in droplet size (Nikolakakis et al., 2015). This effect will increase with increasing proportions of MCC. It is worth noting that the presence of lactose did not oppose the negative effect of MCC on the droplet size.

Table 7: Droplet size and dissolution parameters of gliclazide loaded in solid olive oil based SEDDS compared with its liquid form and plain drug (mean \pm $\mathrm{SD}, \mathrm{n}=3$ ).

\begin{tabular}{cccc}
\hline Formulation & Droplet size $(\mathbf{n m})$ & IDR $(\%$ per $\min )$ & DE $(\%)$ \\
\hline Plain drug & NA & $1.5 \pm 0.05$ & $27.9 \pm 0.78$ \\
B4 & $245 \pm 2.8$ & $8.0 \pm 0.75$ & $86.3 \pm 3.5$ \\
G1 & $265 \pm 3.4$ & $7.8 \pm 0.9$ & $90.6 \pm 0.00$ \\
G2 & $420 \pm 2.3$ & $5.8 \pm 0.34$ & $82.7 \pm 0.5$ \\
G3 & $560 \pm 5.1$ & $5.1 \pm 0.9$ & $69.9 \pm 1.2$ \\
\hline
\end{tabular}

IDR: initial dissolution rate after $10 \mathrm{~min}$.

DE\%: dissolution efficiency \% after $60 \mathrm{~min}$. 


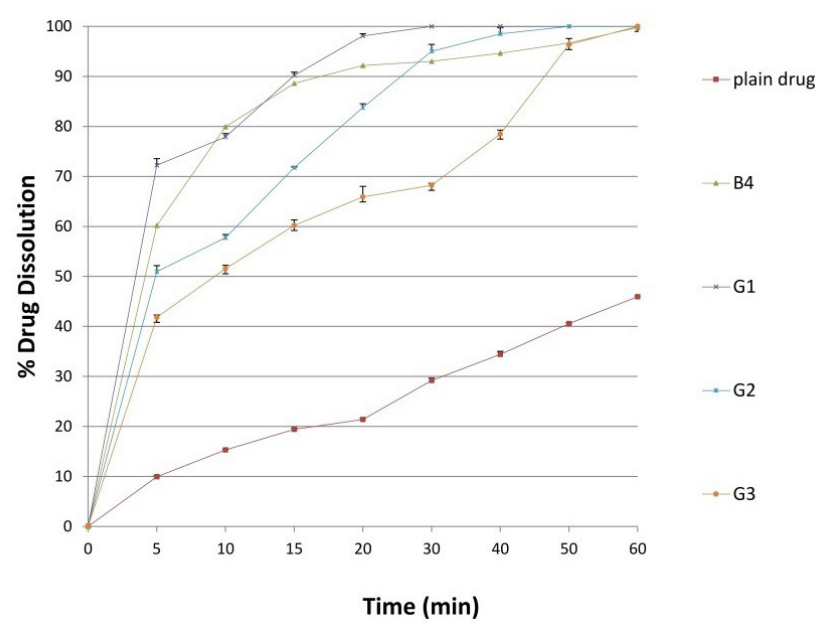

Fig. 9: In vitro dissolution profiles of gliclazide loaded in solid olive oil based SEDDS compared with its liquid form and plain drug $($ mean $\pm S D, n=3)$.

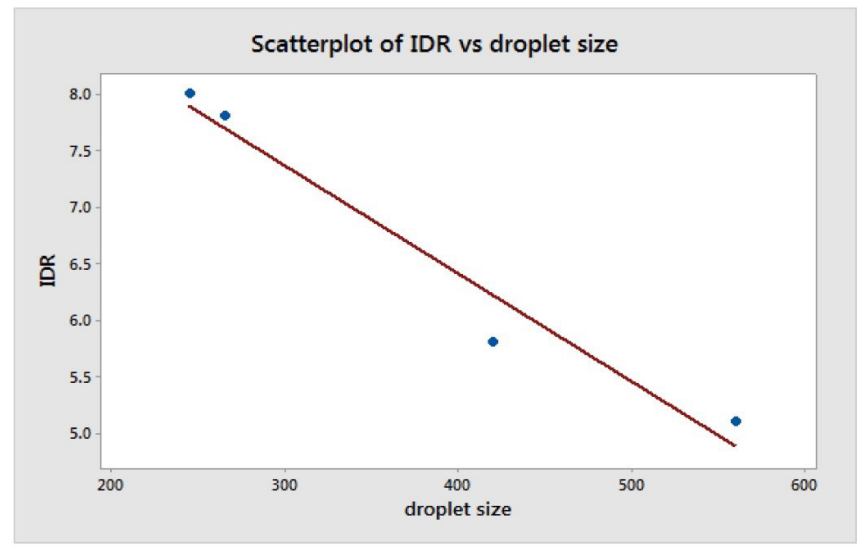

Fig. 10: Correlation analysis of IDR of gliclazide from liquid and solid SEDDS versus droplet size.

\section{In-vitro drug dissolution}

The calculated dissolution parameters (IDR \& DE\%) of the different solid SEDDS (G1-G3) compared with the corresponding liquid formulation (B4) and plain drug are presented in Table 7 and the release behavior is presented in Figure 9. It was clear that dissolution parameters of the different solid SEDDS were much superior $\left(\mathrm{P}=0.00, \mathrm{R}^{2}=94.67 \%\right.$ and $\mathrm{R}^{2}$ adjusted $=$ 92.54\%) when compared with the plain drug. About 4.2 and 2.9folds increase in IDR and DE\%, respectively of gliclazide from solid SEDDS formulations when compared with its plain form. Small droplet size of the formed nanoemulsion after the dispersion of the solid SEDDS results in a large surface area exposed for dissolution medium and hence rapid drug dissolution (Dixit and Nagarsenker, 2008; Cho et al., 2016).

Interestingly, for IDR and DE, there was no significant difference $(\mathrm{P}>0.05)$ between liquid and solid SEDDS containing less adsorbent ratio (G1). However, gliclazide dissolution parameters from the other solid SEDDS were significantly (IDR: $\mathrm{P}=0.003, \mathrm{R}^{2}=80.25 \%$ and $\mathrm{R}^{2}$ adjusted $=72.84 \%, \mathrm{DE} \%: \mathrm{P}=0.00$, $\mathrm{R}^{2}=96.44 \%$ and $\mathrm{R}^{2}$ adjusted $=95.1 \%$ ) reduced than the liquid SEDDS. This result may be attributed to rapid emulsification and small droplet size of the reconstituted dispersion. On the other hand, the reduced dissolution parameters of the preparations containing higher amounts of adsorbent (G2, G3) may be explained on the basis of increased droplet size of the solid-SEDDS after dispersion which is inversely proportional to the dissolution rate.

Correlation analysis revealed that there was a good correlation between the droplet size of the resultant nanoemulsions of the dispersed solid SEDDS and IDR values (Pearson correlation $=-0.980, \mathrm{P}=0.020$ ), Figure 10 .

\section{CONCLUSION}

Olive oil based self-emulsifying delivery system containing 30\% of oil and Tween 80: propylene glycol in $4: 1 \mathrm{w} / \mathrm{w}$ can be successfully developed into solid form by mixing with a mixture of microcrystalline cellulose and lactose as an adsorbent in a weight ratio of 2:1 w/w. The solid self-emulsifying system of gliclazide (Formulation G1) showed improved dissolution properties which may be promising to overcome the problem of inter and intrasubject variability in bioavailability. In addition, the presence of olive oil in the formulation is expected to augment the antidiabetic effect of gliclazide which may confer an added value to the developed preparation. Future in vivo studies will be recommended.

\section{CONFLICT OF INTEREST}

The author discloses no possible conflicts of interest.

\section{REFERENCES}

Abdalla A, Klein S, Mäder K. A new self-emulsifying drug delivery system (SEDDS) for poorly soluble drugs: Characterization, dissolution, in vitro digestion and incorporation into solid pellets. Eur J Pharm Sci, 2008; 3(5):457-464.

Aboutaleb HA, Kharshoum RM, Ismail HR. Formulation and optimization of solid self-nanoemulsifying system using porous carriers for oral delivery of cinnarizine. Int J Pharm Pharm Sci, 2016; 8(1):433-438. table.html.

ACCU Dyne Test ${ }^{\mathrm{TM}}$. Available at: www.accudynetest.com/visc

Agubata CO, Nzekwe IT, Obitte NC, Ugwu CE, Attama AA, Onunkwo GC. Effect of oil, surfactant and co-surfactant concentrations on the phase behavior, physicochemical properties and drug release from self-emulsifying drug delivery systems. J Drug Discov Develop and Deliv, 2014; 1(1):1-7.

Amemiya T, Mizuno S, Yuasa H, Watanabe J. Emulsion type new vehicle for soft gelatin capsule available for preclinical and clinical trials: stabilization of new vehicle containing vitamin K2 with PEG 6000. Xenobiotics, 1999; 14(5):392-398.

Azeem A, Rizwan M, Ahmad FJ, Iqbal Z, Khar RK, Aqil M, Talegaonkar S. Nanoemulsion components screening and selection: A technical note. AAPS Pharm Sci Tech, 2009; 10:69-76.

Bagwe RP, Kanicky JR, Palla BJ, Patanjali PK, Shah DO Improved drug delivery using microemulsions: Rationale, recent progress, and new horizons. Crit Rev Ther Drug Carrier Syst, 2001; 18:77-140.

Basalious EB, Shawky N, Badr-Eldin SM. SNEDDS containing bioenhancers for improvement of dissolution and oral absorption of lacidipine. I: development and optimization. Int J Pharm, 2010; 391:203211.

Berraaouan A, Abid S, Bnouham M. Antidiabetic oils. Current Diabetes Reviews, 2013; 9(6):499-505.

Bhagwat DA, D'Souza JI. Development of solid selfmicroemulsifying drug delivery system with neusilin UF-2 for enhanced dissolution rate of telmisartan. Int J Drug Dev \& Res, 2012; 4(4):398-407.

Bhandari V, Avachat A. Formulation and characterization of self 
emulsifing pellets of carvedilol. Braz J Pharm Sci, 2015; 51(3):663-671. Bhikshapathi D, Madhukar P, Kumar BD, Kumar GA. Formulation and characterization of pioglitazone $\mathrm{HCl}$ self-emulsifying drug delivery system. Pharm Lett, 2013; 5(2):292-305.

Biswal S, Sahoo J, Murthy PN, Giradkar, RP, Avari JG. Enhancement of dissolution rate of gliclazide using solid dispersions with polyethylene glycol 6000. AAPS Pharma Sci Tech, 2008; 9(2):563-570.

Biswal S, Sahoo J, Murthy PN. Physicochemical properties of solid dispersions of gliclazide in polyvinyl pyrrolidone K-90. AAPS Pharm Sci Tech, 2009; 10(2):329-334.

Chen ZQ, Liu Y, Zhao JH, Wang L, Feng NP. Improved oral bioavailability of poorly water-soluble indirubin by a supersaturatable selfmicroemulsifying drug delivery system. Int J Nanomed, 2012; 7:11151125 .

Cho H, Kang J, Ngo L, Tran P, Lee Y. Preparation and evaluation of solid-self-emulsifying drug delivery system containing paclitaxel for lymphatic delivery. J Nanomater, 2016; Article ID 3642418: 14 pages.

Craig DQM. The use of self-emulsifying systems as a means for improving drug delivery. Bull Tech Gattefossé, 1993; 86:21-31.

Czajkowska-Kośnik A, Szekalska M, Amelian A, Szymańska E, Winnicka K. Development and evaluation of liquid and solid selfemulsifying drug delivery systems for atorvastatin. Molecules, 2015; 20:21010-21022.

Dixit RP, Nagarsenker MS. Self-nanoemulsifying granules of ezetimibe: Design, optimization and evaluation. Eur J Pharm Sci, 2008; 35:183-192.

Dokania S, Joshi AK. Self-microemulsifying drug delivery system (SMEDDS) - challenges and road ahead. Drug Delivery, 2015; 22(6).

El-Laithy HM. Self-nanoemulsifying drug delivery system for enhanced bioavailability and improved hepatoprotective activity of biphenyl dimethyl dicarboxylate. Curr Drug Deliv, 2008; 5:170-176.

Fatouros DG, Deen GR, Arleth L, Bergenstahl B, Nielsen FS, Pedersen JS, Mullertz A. Structural development of self nano emulsifying drug delivery systems (SNEDDS) during in vitro lipid digestion monitored by small-angle X-ray scattering. Pharm Res, 2007; 24:1844-1853.

Franceschinis E, Bortoletto C, Perissutti B, Dal Zotto M, Voinovich D, Realdon N. Self-emulsifying pellets in a lab-scale high shear mixer: Formulation and production design. Powder Technology, 2011; 207:113-118.

Franceschinis E, Voinovich D, Grassi M, Perissutti B, FilipovicGrcic J, Martinac A, Meriani-Merlo F. Self-emulsifying pellets prepared by wet granulation in high-shear mixer: influence of formulation variables and preliminary study on the in vitro absorption. Int J Pharm, 2005; 291:87-97.

Gershanik T, Benita S. Self-dispersing lipid formulations for improving oral absorption of lipophilic drugs. Eur J Pharm Biopharm; 2000; 50:179-188.

Gurram AK, Deshpande PB, Kar SS, Nayak YU, Udupa N, Reddy MS. Role of components in the formation of self-microemulsifying drug delivery systems. Indian J Pharm Sci, 2015; 77(3):249-257.

Harrower AD. Comparison of efficacy, secondary failure rate and complications of sulfonylurea. J Diabetes Complicat, 1994; 8:201-203.

Harshal M, Tanvir S, Dheera B, Rajendra WD. Design and development of solid self-micro-emulsifying drug delivery system (SMEDDS) of fenofibrate. Int J Pharm Pharm Sci, 2011; 3(4):163-166.

Hegazi R, El-Gamal M, Abdel-Hady N, Hamdy O. Epidemiology of and risk factors for type 2 diabetes in Egypt. Annals of Global Health, 81(6):814-820.

Iosio T, Voinovich D, Grassi M, Pinto JF, Perissutti B, Zacchigna M, Quintavalle U, Serdoz F. Bi-layered self-emulsifying pellets prepared by co-extrusion and spheronization: Influence of formulation variables and preliminary study on the in vivo absorption. Eur J Pharm Biopharm, 2008; 69:686-697.

Jaiswal P, Aggarwal G, Harikumar SL, Singh K. Development of self-microemulsifying drug delivery system and solid-self-microemulsifying drug delivery system of telmisartan. Int J Pharm Investig, 2014; 4(4):195-
206.

Jung YJ, Dong YS, Lee SH, Kim KH, Yoon DS, Lee KH Enhanced solubility and dissolution rate of itraconazole by a solid dispersion technique. Int J Pharm, 1999; 187:209-218.

Kaithwas G, Majumdar DK. In vitro antioxidant and in vivo antidiabetic, antihyperlipidemic activity of linseed oil against streptozotocin-induced toxicity in albino rats. Eur J Lipid Sci Technol, 2012; 114:1237-1245.

Kallakunta VR, Bandari S, Jukanti R, Veerareddy PR. Oral self-emulsifying powder of lercanidipine hydrochloride: Formulation and evaluation. Powder Technology, 2012; 221:375-382.

Kallakunta VR, Eedara BB, Jukanti R, Ajmeera RK, Suresh Bandari SA. Gelucire 44/14 and labrasol based solid self-emulsifying drug delivery system: formulation and evaluation. J Pharm Invest, 2013; 43:185196.

Khan KA. The concept of dissolution efficiency. J Pharm Pharmacol, 1975; 27:48-49.

Khedekar K, Mittal S. Self emulsifying drug delivery system: A review. Int J Pharm Sci Res, 2013; 4(12):4494-4497.

Lawrence MJ, Rees GD. Microemulsion-based media as novel drug delivery systems. Adv Drug Deliv Rev, 2009; 45:89-121.

Levy MY, Benita S. Drug release from submicronized O/W emulsion: a new in vitro kinetic evaluation model. Int J Pharm, 1990; 66(13):29-37.

Li L, Yi T, Wai-Kei Lam C. Effects of spray-drying and choice of

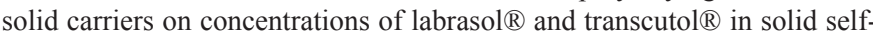
microemulsifying drug delivery systems (SMEDDS). Molecules, 2013; $18: 545-560$

Mahajan HS, Girnar GA, Nerkar P. Dissolution and bioavailability enhancement of gliclazide by surface solid dispersion using spray drying technique. Indian J Novel Drug Deliv, 2012; 4(2):115-124.

Mehrnia MA, Jafari SM, Zadeh BS, Maghsoudlou Y. Crocin loaded nano-emulsions: factors affecting emulsion properties in spontaneous emulsification. Int J Biol Macromol, 2016; 84:261-267.

Miryala V, Kurakula M. Self-nano emulsifying drug delivery system (SEDDS) for oral delivery of atorvastatin-Formulation and bioavailability studies. JDDT, 2013; 3:131-142.

Mohanvarma SK, Padavala MV. Oral lipid-based drug delivery systems - an overview. Acta Pharm Sin B, 2013; 3(6):361-372.

Mosca M, Cuomo F, Lopez, F, Ceglie A. Role of emulsifier layer, antioxidants and radical initiators in the oxidation of olive oil-inwater emulsions. Food Res Int, 2013; 50:377-383.

Nepal PR, Han HK, Choi HK. Preparation and in vitro-in vivo evaluation of Witepsol H35 based selfnanoemulsifying drug delivery systems (SNEDDS) of coenzyme Q10. European J Pharm Sci, 2010; 39(4), 224-232.

Nigade PM, Patil S, Shradha S. Self emulsifying drug delivery system (sedds): a review. IJPBS, 2012; 2(2):42-52.

Nikolakakis I, Panagopoulou A, Salis A, Malamataris S. Relationships between the properties of self-emulsifying pellets and of the emulsions used as massing liquids for their preparation. AAPS Pharm Sci Tech, 2015; 16(1):129-139.

Nipun TS, Ashraful Islam SM. SEDDS of gliclazide: Preparation and characterization by in-vitro, ex-vivo and in-vivo techniques. Saudi Pharm Journal, 2014; 22(4):343-348.

Ostertag F, Weiss J, McClements DJ. Low-energy formation of edible nanoemulsions: factors influencing droplet size produced by emulsion phase inversion. J Colloid Interface Sci, 2012; 388:95-102.

Palmer KJ, Brogden RN. Gliclazide, an update of its pharmacological properties and therapeutic efficacy. Drugs, 1993; 46:92125 .

Parekh VJ, Desai ND, Shaikh MS, Shinde UA. Self nanoemulsifying granules (SNEGs) of meloxicam: preparation, characterization, molecular modeling and evaluation of in vivo antiinflammatory activity. Drug Dev Ind Pharm, 2017; 43(4).

Pouton CW. Lipid formulations for oral administration of 
drugs: non-emulsifying, self-emulsifying and 'self-microemulsifying' drug delivery systems. Eur J Pharm Sci, 2000; 11:S93-S98.

Pouton CW. Formulation of poorly water-soluble drugs for oral administration: physicochemical and physiological issues and the lipid formulation classification system. Eur J Pharm Sci, 2006; 29:278-287.

Saifee M, Zarekar S, Rao VU, Zaheer Z, Soni R, Burande S. Formulation and In vitro evaluation of solid-self- emulsifying drug delivery system (SEDDS) of Glibenclamide. AJADD, 2013; 1(3):323-340.

Samarji R, Balbaa M. Anti-diabetic activity of different oils through their effect on arylsulfatases. J Diabetes Metab Disord, 2014; 13:116.

Sapkal NP, Kilor VA, Bhusari KP, Daud AS. Evaluation of some methods for preparation of gliclazide- $(-$-cyclodextrin inclusion complexes. Trop J Pharm Res, 2007; 6(4):833-840.

Seo YG, Kim DH, Ramasamy T, Kim JH, Marasini N, Oh YK, Kim DW, Kim JK, Yong CS, Kim JO, Choi HG. Development of docetaxelloaded solid self-nanoemulsifying drug delivery system (SNEDDS) for enhanced chemotherapeutic effect. Int J Pharm, 2013; 452:412-420.

Shahavia MH, Hosseinia M, Jahanshahia M, Meyer RL, Najafpour G. Evaluation of critical parameters for preparation of stable clove oil nanoemulsion. Arabian Journal of Chemistry, 2015.

Shavi GV, Kumar AR, Usha YN, Armugam K, Ranjan O, Ginjupalli K, Pandey S, Udupa N. Enhanced dissolution and bioavailability of gliclazide using solid dispersion techniques. Int J Drug Deliv, 2010; 2:49-57.

Suresh PK, Sharma S. Formulation and in-vitro characterization of self-nanoemulsifying drug delivery system of cinnarizine. Pharmacie Globale (IJCP), 2011; 9(8):1-6.

Talegaonkar S, Azeem A, Ahmad FJ, Khar RK, Pathan SK, Khan
ZI. Microemulsions: a novel approach to enhanced drug delivery. Recent Pat Drug Deliv Formul, 2008; 2:238-257.

Tuleu C, Newton M, Rose MJ, Euler D, Saklatvala R, Clarke A, Booth S. Comparative bioavailability study in dogs of a self-emulsifying formulation of progesterone presented in a pellet and liquid form compared with an aqueous suspension of progesterone. J Pharm Sci, 2004; 93:14951502 .

Yi T, Wan J, Xu H, Yang X. New solid self-microemulsifying formulation prepared by spray-drying to improve the oral bioavailability of poorly water soluble drugs. Eur J Pharm Biopharm, 2008; 70:439-444.

Wankhade VP, Atram SC, Nishan N Bobade NN, Pande SD, Tapar KK. Formulation and optimization of SNEDDS of gliclazide using response surface methodology. Asian J Pharm, 2012; 6(4):289.

Yin YM, Cui FD, Mu CF, Choi MK, Kim JS, Chung SJ, Shim CK, Kim DD. Docetaxel microemulsion for enhanced oral bioavailability: preparation and in vitro and in vivo evaluation. J Controlled Release, 2009; 140:86-94.

Zambiazi RC, Przybylski R, Zambiazi MW, Mendonca CB. Fatty acid composition of vegetable oils and fats. Curitiba, 2007; 25(1):111-120.

Zeing L, Xin X, Zhang Y. Development and characterization of promising Cremophor EL-stabilized o/w nanoemulsions containing shortchain alcohols as a cosurfactant. RSC Adv, 2017; 7:19815-19827.

How to cite this article:

Balata GF. Formulation and Evaluation of Gliclazide in Vegetable Oil-Based Self Emulsifying Delivery System. J App Pharm Sci, 2018; 8(09): 023-033. 